\title{
A DESCRIPTIVE STUDY ON USE OF FAMILY PLANNING METHODS BY MARRIED REPRODUCTIVE AGED WOMEN IN BHUTANESE REFUGEE CAMPS OF EASTERN NEPAL
}

RB Rayamajhi' ${ }^{*}$, SS Budhathoki ${ }^{1}$, A Ghimire ${ }^{1}$, B Neupane ${ }^{2}$, A Paudel $^{2}$, KM Paudel ${ }^{3}$, PK Pokharel ${ }^{1}$

\author{
${ }^{1}$ School of Public Health and Community Medicine, B. P. Koirala Institute of Health Sciences, Dharan, Nepal \\ ${ }^{2}$ Department of Obstetrics and Gynaecology, College of Medical Sciences, Bharatpur, Chitwan, Nepal \\ ${ }^{3}$ Senior Consultant Paediatrician, Lumbini Zonal Hospital, Butwal, Rupandehi, Nepal \\ *Correspondence to: Dr. Rajan Bikram Rayamajhi, School of Public Health and Community Medicine, B. P. Koirala Institute of Health Sciences, Dharan, Nepal. \\ Email: rayamajhi.rajan@hotmail.com
}

\begin{abstract}
Informed choice is an important aspect for decision making regarding the uptake and adherence to family planning methods. The women in Bhutanese Refugee camps of Nepal have family planning services available through the primary health centers located within the refugee camps. Objective: This study was conducted to find out the factors related to use of family planning methods by married women of reproductive age in the Bhutanese Refugee camps of eastern Nepal. Results: The study has a response rate of $100.0 \%$. The mean age of the respondents was 29.3 years. Primary health center of the camp was the most commonly known (60.9\%) place for accessing family planning methods. One third of the respondents discussed family planning methods with their husbands. The rest didn't discuss as they felt intimidated by their husband. Almost $90.0 \%$ respondents had ever used a family planning method and the most common reason for using a method was the influence of a peer (62.3\%). Conclusion: Further studies on exploring the discussion between husband and wives regarding the use of family planning is needed so that appropriate interventions can be identified. The role of the peer could be further explored to assist women to make an informed choice of their family planning method.
\end{abstract}

Key words: Bhutanese Refugees, Contraception, Family Planning, Informed Choice, Nepal.

\section{INTRODUCTION}

According to the World Health Organisation (WHO), family planning allows individuals and couples to anticipate and attain their desired number of children, the spacing and timing of their births. ${ }^{1}$ Use of contraception leads to smaller family resulting better quality of life. Underutilisation of FP measures of any form results in a large family leading to chaos and poor quality of life. ${ }^{2}$ Family planning is one of the many strategies women can use to exercise autonomy leading to better lives. ${ }^{3}$ Consumers must be allowed to choose family planning method on their own with health care professional counselling them enough so that they can decide on their own. ${ }^{2}$ Globally, contraceptive use has risen from $54.0 \%$ in 1990 to $63.0 \%$ in 2007 . Regionally, the proportion of married women aged 15-49 years reporting use of any contraceptive method has raised minimally between 1990 and 2007 from $17.0 \%$ to $28.0 \%$ in Africa, $57.0 \%$ to $67.0 \%$ in Asia and $62.0 \%$ to $72.0 \%$ in Latin America and the Caribbean with significant variation among countries in this region. ${ }^{1}$

Bhutanese Refugees are one of the vulnerable marginalized groups in Nepal whose problems get the prime importance but are not adequately addressed. The family planning methods are available free of cost. Despite that, there seems a gap between family planning promotion and its availability. Hormonal methods (oral/injectable) and barrier methods (male/female condoms) are available in the health centre. Implants (Norplant) and intrauterine contraceptive devices (IUCD) are availed on demand basis. For permanent sterilization they are taken to nearby centres free of cost. Health 
promotion teachings are frequently given to refugee community by health professionals from primary health centers. This has made them aware about the importance and availability of different family planning methods in their health centres. In this situation, some of them are willing to adopt family planning measures while others don't. ${ }^{4}$

Decision to initiate or adhere to the use of family planning methods vary in different women groups influenced by many factors including literacy. ${ }^{5}$ Spousal communication and male involvement in family planning are important factors influencing decision making among women and couples. ${ }^{6,7}$ Limited studies can be found in context to Bhutanese Refugees and family planning ${ }^{8}$. There is a need to explore the factors among the refugee women. Thus it is warranted to see the baseline data on the factors related to the use of family planning in the women living in the refugee camps of eastern Nepal.

\section{OBJECTIVE}

The objective of the study was to describe the factors related to the use of family planning methods among married women of reproductive age in Bhutanese Refugee camps of eastern Nepal.

\section{METHODS AND MATERIALS}

A cross-sectional study was carried out among 350 married women of reproductive age in Bhutanese Refugee camps of eastern Nepal. This study describes the decision making on use of family planning among the married women of reproductive age group (15 49 years) in Bhutanese refugee population residing in the eastern part of Nepal. This study is a part of the larger study on family planning preferences among refugee women published in 2014 . The sample size calculation can be found in the study ${ }^{8}$.

The respondents were recruited among married women of reproductive age who were residing in the camps. They were selected using systematic random sampling from the list obtained from Camp Management Committee (CMC). Refugee women living outside the camp, not seeking health care services from the camp were excluded. Data were collected by face to face interview using pretested semi-structured questionnaire. Coded data were entered into MS Windows Excel. Analysis was performed using Statistical Package for Social Sciences (SPSS) version 17.0.

Ethical clearance was obtained from the Institutional Review Board (IRB) of B. P. Koirala Institute of Health Sciences prior to the study. Participants were well explained about the purpose of the study and involvement was voluntary. There was no incentive provided to the participants for providing the data. Privacy and confidentiality was maintained for the collected data.

\section{RESULTS}

$100.0 \%$ of the participants responded to the questionnaire $(n=350)$ with the mean age of $29.3 \pm 7.6$ years, the youngest one was 18 years and the oldest was 49 years of age.

The age at first marriage showed the trend of early marriage among the refugees where almost 35.0\% were found to be married before the age of 19 years. The mean age of first marriage was found to be $20.3 \pm 3.0$ years. Corresponding with early marriage, $2.6 \%$ of the women in refugee camp had their first pregnancy before 19 years of age. The mean age of first pregnancy was found to be $22.1 \pm 3.7$ years.

Knowledge about places from where the FP methods are available

Three out of five of the respondents recognized PHC (Primary Health Care Centre for Refugee within the Camp) as the source for availability of contraception. A very small fraction of respondents (5.7\%) identified outreach clinic as the place where FP methods were available (Fig. 1)

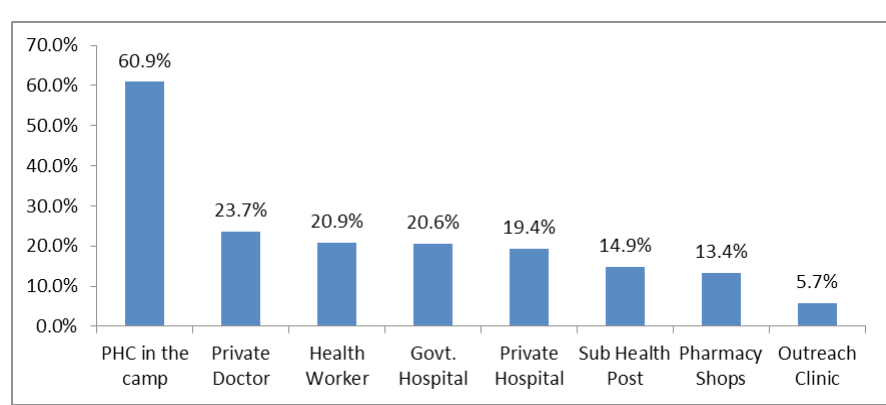

Figure 1: Knowledge among the women regarding the places from where family planning methods were available $(n=350)$

\# Multiple responses 
Attitude towards family planning methods

Approximately 3/5th of the respondents didn't discuss about the use of family planning methods with their partners. It was found that almost $40.0 \%$ of the respondents didn't receive the informed choice of family planning methods from the health professionals. About $15.4 \%$ of the respondents had unintentional pregnancy during their lifetime. Of those that had unintentional pregnancy, $48.1 \%$ experienced contraception failure. Respondents were divided into equal proportions when they were inquired about the desire to have child. (Table 1)

Table 1: Attitude towards Family Planning Methods among the respondents

\begin{tabular}{|c|c|c|}
\hline Characteristics & Number & $\%$ \\
\hline \multicolumn{3}{|c|}{ Discussion with spouse about FP $(\mathrm{N}=350)$} \\
\hline Yes & 112 & 32.0 \\
\hline No & 238 & 68.0 \\
\hline \multicolumn{3}{|c|}{ Reasons for not discussing about FP with Spouse $(\mathrm{N}=238$} \\
\hline Male dominance & 204 & 85.7 \\
\hline Peer influence & 27 & 11.3 \\
\hline Hesitation & 7 & 2.9 \\
\hline \multicolumn{3}{|c|}{ Informed Choice of FP Methods ( $N=350)$} \\
\hline Yes & 211 & 60.3 \\
\hline No & 139 & 39.7 \\
\hline \multicolumn{3}{|c|}{ Ever Unintentional Pregnancy $(\mathrm{N}=350)$} \\
\hline Yes & 54 & 15.4 \\
\hline No & 296 & 84.6 \\
\hline \multicolumn{3}{|c|}{ Reasons behind Unintentional Pregnancy $(\mathrm{N}=54)$} \\
\hline No use of FP methods & 21 & 38.8 \\
\hline Failure of FP methods & 26 & 48.1 \\
\hline Irregular use of FP methods & 7 & 12.9 \\
\hline \multicolumn{3}{|l|}{ Desire for Children $(\mathrm{N}=350)$} \\
\hline Yes & 175 & 50.0 \\
\hline No & 175 & 50.0 \\
\hline
\end{tabular}

Practices of family planning methods by respondents

This study highlighted the fact of ever use of family planning methods among respondents being almost $89.0 \%$ and the currents users being $62.3 \%$. (Table 2) Almost $62.0 \%$ of the current users recognized peer influence as the main reason behind the use of family planning methods followed by health problems (12.8\%).
Approximately, $7.0 \%$ of the current pregnancy was found to be unintentional among the respondents. Almost $3 / 4^{\text {th }}$ of them had some form of unmet needs of family planning ever in their life.

Table 2: Practices of family planning methods among the respondents

\begin{tabular}{|l|l|l|}
\hline \multicolumn{3}{|c|}{ Family planning method practices } \\
\hline Characteristics & Number & Percentage \\
\hline Ever use of FP methods(N=350) & 313 & 89.4 \\
\hline Yes & 37 & 10.6 \\
\hline No & 37 & 62.3 \\
\hline Reasons for choosing the FP Methods (N=218) \\
\hline Peer Influence & 136 & 12.8 \\
\hline Health Problems & 28 & 10.5 \\
\hline New Experience & 23 & 7.3 \\
\hline In-Laws Choice & 16 & 4.1 \\
\hline Less Tedious & 9 & 1.8 \\
\hline Husband's choice & 4 & 0.9 \\
\hline Convenience & 2 & \\
\hline Current pregnancy (N=350) & 325 \\
\hline Intentional & 25 & 92.9 \\
\hline Unintentional & 7.1 \\
\hline Ever unmet needs (N=350) & 265 \\
\hline Yes & 85 & 75.7 \\
\hline No & 24.3 \\
\hline
\end{tabular}

\section{DISCUSSION}

This study showed that early marriage was prevalent among the Bhutanese refugee population. Early marriage and teenage pregnancy could have a significant detrimental effect on maternal and child health. Almost one third of the respondents were married early in their lives, i.e. below the age of 19 years. Nepal's country-wide data also shows that early marriage is quite prevalent. About $60.0 \%$ of the girls were married by the age of 18 years. ${ }^{9}$ This was even higher in Nepal. It was found to be almost $40.0 \%$ in resettled area of Delhi. ${ }^{10}$ Similarly, another study done by Kanan in slums of Delhi observed that more than $76.0 \%$ of the girls were married before the age of 18 years. ${ }^{11}$

Almost $23.0 \%$ of the women had their first child (C) 2016, JCMC. All Rights Reserved 
before the age of 19 which was much less in compare to a similar study done in Delhi by A. Khokhar. ${ }^{10}$ The study found almost $76.0 \%$ of the women had their first child before the age of 19 years. One fourth of the women in reproductive age group possessed high risk pregnancy which ultimately would boost the maternal mortality rate. Similarly, another study done in India among the adolescents revealed that about $17.0 \%$ of the adolescents were pregnant with their first child before 19 years of age..$^{12}$ In Nepal, about $19.0 \%$ of the women had their first baby or were pregnant with their first child in between the age of $15-19$ years. ${ }^{9}$

Peer influence played a vital role among many of the respondents in choosing the family planning methods followed by the desire to experience new family planning methods and individual health problems. This finding was different from the study carried out in Dehradun District in India in which presence of at least one male child in the family was the main reason behind the contraception use among respondents termed as 'Male Child Syndrome'13.

Family planning methods were provided free of cost by AMDA PHCP for BR to its consumers. About $61.0 \%$ of the respondents in this study identified PHC (Primary Health Centre within the camp) as the source for family planning methods followed by health workers. This was almost similar to Nepalese scenario where almost $56.0 \%$ of the respondents had been provided the informed choice by the health professionals. ${ }^{9}$ This was similar to the finding of the study by S. Pandey in Makwanpur where majority $(80.2 \%)$ of the respondents replied Health centre and Hospital as the source of contraception. ${ }^{14}$ Government sector institutions were considered to be the source for contraception by majority of the Nepalese population. ${ }^{9}$ The reason behind two fifth of the respondents not identifying PHC as the source of contraception was because the contraceptive methods were available in the maternal and child health clinic only. A crowd was always present there for maternal and child health services. This repelled the possible family planning method consumers from taking the services due to hesitation and awkwardness. This would also decrease the opportunities for the health professionals to provide informed choice about the family planning methods to the users. The other main reason was the $\mathrm{MCH}$ clinic where family planning services were available was closed during the holidays and after working hours so consumers couldn't receive the service and were compelled to go elsewhere.

Refugee society was similar to Nepalese society where discussion about family planning methods and sex education was still a taboo. This was proved by the findings of this study where almost $68.0 \%$ of the women deny having discussion about use of family planning methods. About two third of the women never discussed about family planning methods with their husbands. ${ }^{9}$

\section{CONCLUSION}

While there is availability of the services in the camp PHC and the women have information about the family planning methods and its availability, there could be cultural and societal issues that need to be further explored so that the women would be actively involved in making informed choice regarding the use of family planning methods in the Bhutanese Refugee camps of Nepal. The discussion with spouses regarding family planning among women needs further exploration so that the barriers are identified to address this gap. This problem needs to be explored in much depth and addressed both from the society and government perspective.

\section{ACKNOWLEDGEMENTS}

My sincere acknowledgements to Dr. Bharati Shakya, Dr. Kumar Gaurav, Dr. Pranil Man Singh Pradhan, Dr. Khem Raj Sharma, Dr. Dipesh Tamrakar, Dr. Prajwol Pyakhurel, Dr. Puspanjali Adhikari, Dr. Netrika Prasad Madhen Limbu, Dr. Surya Bahadur Parajuli and all the participants without whom this study would have been never possible.

\section{REFERENCES}

1. World Health Organisation. Family Planning. Fact Sheethttp://www.who.int/mediacentre /factsheets/ fs351/en/index.html (2014, accessed 21 August 2014).

2. Park K. Park's Textbook of Preventive and Social Medicine. 21st ed. Jabalpur: Banarasidas Bhanot, 2011. 
Rayamajhi et al, Journal of Chitwan Medical College 2016; 6(16)

3. Barnett B, Konate M, Mhloyi M, et al. The impact of family planning on women's lives: findings from the women's studies project in Mali and Zimbabwe. Afr J Reprod Health 2011;7:27-38.

4. United Nations High Commissioner for Refugees. UNHCR regional operations profileSouth Asia - Nepal.http://www.unhcr.org/ pages/49e487856.html (2014).

5. Aggarwal AR, Singh P. Analysis of adoption preference of Family Planning methods through multiple logistic regression. Indian J Community Med;28.

6. Undelikwo VA, Osonwa OK, Ushie MA, et al. Family Planning Behaviours and DecisionMaking among Couples in Cross River State, Nigeria. Int J Learn Dev 2013;3:100-120.

7. Ijadunola MY, Abiona TC, Ijadunola KT, et al. Male Involvement in Family Planning Decision Making in Ile-Ife, Osun State, Nigeria. Afr J Reprod Health 2010;14:45-52.
8. Rayamajhi RB, Paudel IS, Bhattarai S, et al. Practice of Contraception and Quality of life among Bhutanese. Glob Med Res K Interdiscip 2014;14:16-21.

9. Ministry of Health and Population (MOHP) Nepal. Nepal Demographic and Health Survey 2011. Kathmandu, 2012.

10. Khokhar A, Mehra M. Contraceptive use in women from a resettled area in Delhi. Indian J Community Med 2005;30:21.

11. Kanan K. Delhi slum girls marry early: Report. The Hindu, 26 August 2002.

12. Jejeebhoy SJ. Adolescent sexual health and reproductive behavior. a review of the evidence from India. 3, Washington, 1996.

13. Kansal A, Chandra R, Kandpal SD, et al. Epidemiological correlates of contraceptive prevalence in rural population of Dehradun District. Indian J Community Med;30.

14. Pandey S, Karki S, Pradhan A. Practice of contraceptives. J Inst Med;31. 